\title{
Kepentingan Rusia dalam Proyek Pembangunan \\ Pipa Gas Turkish Stream tahun 2014-2016
}

\author{
Rifka Amalia ${ }^{1}$ \& Muhammad Yamin ${ }^{2}$
}

\begin{abstract}
This paper aims to analyze Rusia's interest in the development of Turkish Stream Project in 2014 until 2016. Energy is the most notable sector for Russia that can affect the economy-politics. From economy side, energy exports are largely included in state revenues. Politically, energy is a top priority in every political agenda and foreign policy. Energy is one of determining Russia's foreign policy toward its energy importing countries. EU is a region that has dependence on Russian energy, especially natural gas. Therefore Russia sees EU as a great opportunity and wants to dominate European's energy market. So the South Stream project was formed which would deliver Russian natural gas directly to Europe via the Black Sea. This is one of Russia's step to maintain the EU's dependence on Russia and dominating energy market. Unfortunately, this project must be stalled due to the Third Energy Package policy implemented by EU. Russia, with its ambition to dominate the European energy market, has had an alternative project to achieve that ambition. The Turkish Stream project was formed in cooperation between Russia dan Turkey. The project planned not only deliver Russian natural gas to Turkey but also Europe via Greece. Although the negotiations and deliberations of this project were delayed, the project was finally continued.
\end{abstract}

Keywords : Energy, National Interest, Third Energy Package, European Union, Russia.

\begin{abstract}
Abstrak
Artikel ini hendak menganalisa kepentingan Rusia dalam pembangunan proyek "Turkish Stream”. Energi adalah sektor yang paling menonjol bagi Rusia yang dapat mempengaruhi ekonomi-politik. Dari sisi ekonomi, ekspor energi sebagian besar masuk dalam penerimaan negara. Secara politis, energi merupakan prioritas utama dalam setiap agenda politik dan kebijakan luar negeri. Energi adalah salah satu penentu kebijakan luar negeri Rusia terhadap negara pengimpor energinya. UE adalah wilayah yang memiliki ketergantungan terhadap energi Rusia, terutama gas alam. Oleh karena itu Rusia melihat Uni Eropa sebagai peluang yang bagus dan ingin mendominasi pasar energi Eropa. Proyek South Stream yang dibentuk ini akan mengantarkan gas alam Rusia langsung ke Eropa melalui Laut Hitam. Hal ini adalah salah satu langkah Rusia untuk menjaga ketergantungan Uni Eropa terhadap Rusia dan mendominasi pasar energi. Sayangnya, proyek ini harus macet karena kebijakan Third Energy Package yang diimplementasikan oleh UE. Rusia, dengan ambisinya mendominasi pasar energi Eropa, telah memiliki proyek alternatif untuk mencapai ambisi tersebut. Proyek Turkish Stream dibentuk atas kerjasama antara Rusia dan Turki. Proyek ini direncanakan tidak hanya mengantarkan gas alam Rusia ke Turki tapi juga Eropa via Yunani. Meski negosiasi dan pembahasan proyek ini tertunda, proyek tersebut akhirnya dilanjutkan.
\end{abstract}

Kata-kata Kunci: Energi, Kepentingan Nasional, Third Energy Package, Uni Eropa, Rusia.

\section{Pendahuluan}

Energi merupakan sektor terpenting dalam perekonomian Rusia. Dapat dikatakan ekonomi Rusia bergantung pada sektor energi. Sebanyak 57\% PDB Rusia berasal dari minyak (energi) (Movchan, 2015). Pada tahun 2012, Rusia berada di peringkat dua dunia dalam hal produksi gas tahunan, sekitar 19\% dari total produksi dunia. Rusia juga merupakan produsen dan pengekspor utama dari minyak dan gas alam. Dari pendapatan minyak dan gas alam tersebut dapat menyumbang $43 \%$ dari pendapatan anggaran Rusia di tahun 2015 (Kementerian Keuangan Rusia, 2016).

\footnotetext{
${ }^{1}$ Alumni Jurusan Hubungan Internasional FISIP Unsoed

${ }^{2}$ Staf Pengajar Jurusan Hubungan Internasional FISIP Unsoed
} 
Dapat dikatakan, energi memainkan peran penting dalam perekonomian Rusia. Dalam sudut pandang politik, energi dijadikan sebagai alat dalam kebijakan luar negeri dan menjadi prioritas utama dalam agenda kebijakan. Sehingga dapat dikatakan bahwa energi merupakan salah satu hal dalam penentuan kebijakan luar negeri Rusia terhadap negara-negara pengimpor energinya (Shaffer, 2009, hal. 28). Rusia juga menjadikan energi sebagai senjata untuk meningkatkan pengaruhnya di negara-negara Asia Tengah, Byelorussia dan Ukraina (Gidadhubli, 2003). Selain itu, politik energi tersebut digunakan oleh Rusia dalam penentuan harga minyak, proyek pembangunan pipa gas dan juga kerjasama dengan negara transit.

Uni Eropa merupakan pengimpor minyak dan gas alam dari Rusia paling besar hingga saat ini. Bahkan hampir setengah dari kebutuhan gas Uni Eropa diimpor dari Rusia. Menurut data yang dikeluarkan oleh Gazprom (Perusahaan Minyak dan Gas Alam Rusia), pada tahun 2014 pihaknya mengekspor gas alam ke Eropa sebanyak 146,6 $\mathrm{bcm}$. Terjadi kenaikan ekspor di tahun 2015 yaitu sebesasr 158,6 bcm. Jerman dan Italia menjadi negara anggota Uni Eropa yang paling besar mengimpor gas dari Rusia. Selain Jerman dan Italia, negara anggota Uni Eropa yang mengimpor gas Rusia antara lain Perancis, Hungaria, Republik Ceko, Polandia, Austria dan Slovakia. Sedangnya negara pengimpor gas yang tidak tergabung dalam Uni Eropa adalah Ukraina, Turki dan Belarusia (Gazprom Company, 2015).

Ketergantungan negara-negara Uni Eropa terhadap energi Rusia membuat kawasan Uni Eropa menjadi pasar penting bagi perdagangan energi Rusia. Dapat dikatakan terdapat hubungan saling ketergantungan antara Rusia dengan negara-negara Uni Eropa, di mana Rusia membutuhkan Uni Eropa sebagai pasar dan Uni Eropa menbutuhkan energi dari Rusia. Untuk memenuhi kebutuhan tersebut, Rusia dan Uni Eropa membuat rencana proyek penyaluran gas alam, South Stream. South Stream ini akan membawa gas alam dari Rusia menuju Eropa melalui Laut Hitam dengan Bulgaria sebagai pintu masuk ke Eropa. Proyek ini pertama kali diumumkan pada Juni 2007. Tujuan dibangunnya South Stream tersebut adalah untuk menjamin dan meningkatkan keamanan penyaluran energi di Eropa dengan aman, terpercaya dan ramah lingkungan (URS, 2014, hal. 2). Proyek ini diprediksi selesai dibangun pada akhir 2015 dan dapat menyalurkan gas alam di tahun yang sama, dengan catatan pipa gas telah di uji coba terlebih dahulu (Gazprom, hal. 11).

Perjanjian tentang proyek Turkish Stream antara Pemerintah Rusia dengan Pemerintah Turki telah ditandatangani pada 10 Oktober 2016 pada acara 23rd World Energy Congress di Istanbul. 
Gambar 1. Peta Perencanaan Jalur Offshore Pipa Gas Turkish Stream

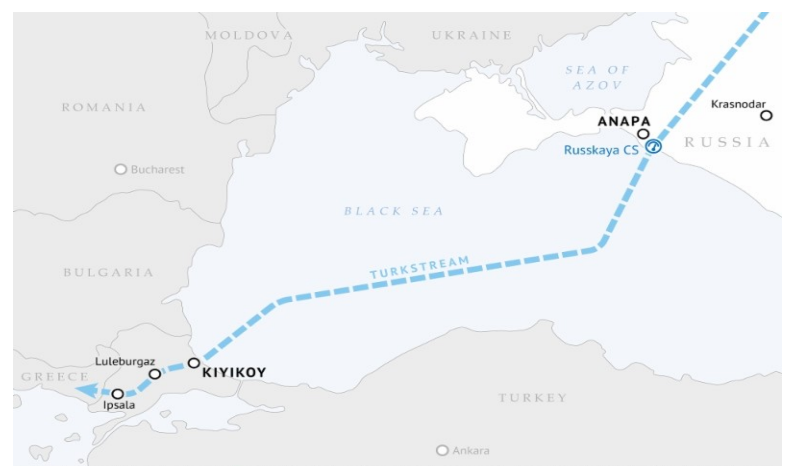

Sumber : Website resmi Gazprom (http://www.gazprom.com/ press/news/2016/september/article287231/)

Pada perjanjian itu meliputi kesepakatan tentang konstruksi dua rangkaian pipa gas dari Rusia ke Turki melalui Laut Hitam, juga rangkaian pipa onshore untuk transit gas ke perbatasan Turki dan negaranegara tetangga. Perjanjian ini dianggap penting karena merupakan kerangka legal bagi kedua pihak (Gazprom Press Release, 2016).

Menindaklanjuti perjanjian tersebut, pada 8 Desember 2016 telah ditandatangani kontrak untuk membangun rangkaian pertama pipa gas offshore dalam proyek Turkish Stream. Perjanjian tersebut ditandatangani oleh South Stream Transport B.V dan Allseas Group S.A. Berdasarkan kontrak tersebut, Allseas akan membangun pipa gas lebih dari $900 \mathrm{~km}$ di dasar laut. Maka dari itu, perusahaan tersebut berencana untuk menggunakan Pioneering Spirit, yang merupakan kapal konstruksi terbesar di dunia yang dilengkapi dengan enam pangkalan pengelasan dan enam pangkalan penyulingan. Perencanaan pembangunan jalur pipa gas tersebut adalah paruh kedua tahun 2017 (Gazprom Press Release, 2016).

\section{Kepentingan Rusia dalam Proyek Pipa Gas Turkish Stream}

Bergantinya proyek South Stream ke proyek Turkish Stream tidak memungkiri bahwa ada kepentingan yang ingin diraih oleh Rusia. Kepentingan-kepentingan Rusia dalam proyek Turkish Stream, antara lain :

\section{Mendominasi Pasar Energi Eropa melalui Turki}

Energi merupakan isu utama bagi Rusia dan Uni Eropa : Uni Eropa membutuhkan keamanan dalam penyaluran energi dan Rusia membutuhkan permintaan gas dari Uni Eropa. Pada tahun 1960an, pembicaraan mengenai kerjasama energi telah dilakukan antara Uni Eropa dan Rusia. Sejak saat itu, pembicaraan mengenai energi terus berlanjut antara Uni Eropa dan Rusia (Piebalgs, 2009). Untuk melihat perkembangan impor energi, terutama gas alam Rusia ke Uni Eropa dapat dilihat pada tabel di bawah ini :

Grafik 2. Impor Uni Eropa terhadap Gas Alam Rusia tahun 1990-2013

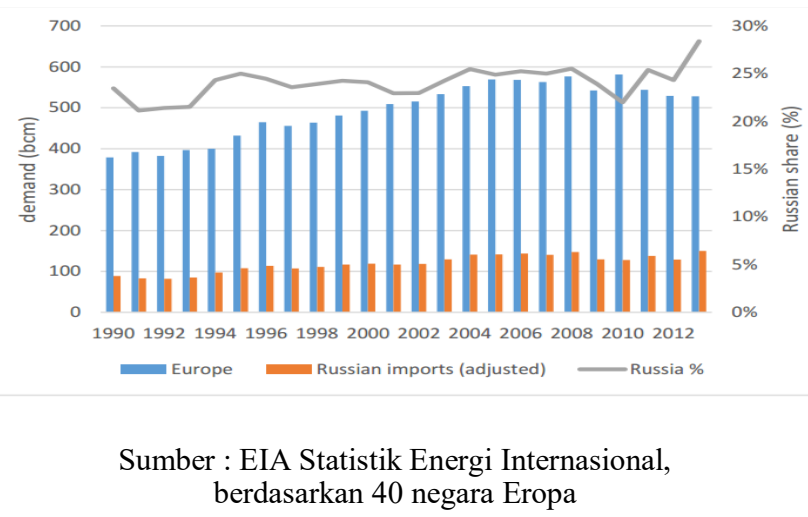


Gambar 3. Peta Impor Uni Eropa terhadap Gas Alam Rusia tahun 2012

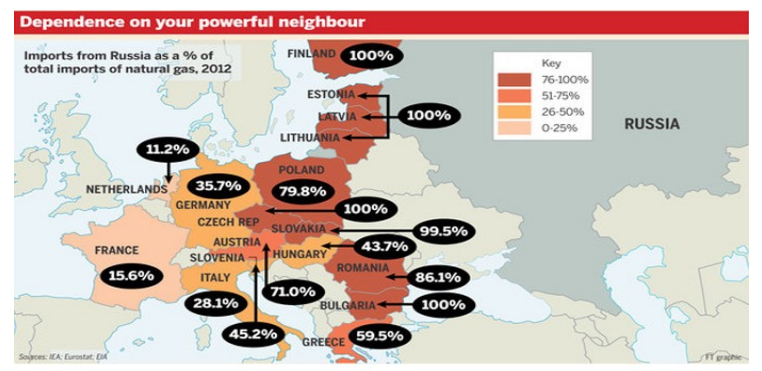

Sumber : Grafik Financial Times berdasarkan IEA

Pada Gambar 3 dapat dilihat bahwa permintaan gas alam Rusia di Uni Eropa sangatlah tinggi. Sejak tahun 1990, impor gas alam dari Rusia terus mengalami kenaikan hingga di tahun 2004. Meskipun tahun-tahun berikutnya sempat mengalami fluktuasi, namun tetap permintaan akan gas alam Uni Eropa kepada Rusia masih tinggi. Jika dilihat lebih mendalam, pada gambar 3 menyajikan peta negara-negara Uni Eropa beserta tingkatan permintaan gas alam dari Rusia. Dalam gambar tersebut menunjukkan bahwa Finlandia, Estonia, Latvia, Lithuania, Republik Ceko, Bulgaria, dan Slovakia merupakan negara-negara yang sangat bergantung pada Rusia. Melihat hal tersebut sudah pasti kawasan Eropa merupakan pasar yang penting bagi Rusia.

Melihat potensi sebesar itu, maka tentu saja proyek South Stream merupakan proyek yang sangat penting bagi Rusia. Proyek South Stream yang bertujuan untuk diversifikasi penyediaan gas alam Rusia ke Selatan hingga Timur Eropa sehingga dapat menjamin keamanan penyediaan gas alam Uni Eropa (Banciu, 2015). Diversifikasi yang mencakup hampir seluruh wilayah Eropa tersebut dapat meningkatkan dominasi Rusia akan pasar energi Eropa.

Namun sayangnya hal tersebut bertentangan dengan keinginan Uni Eropa yang ingin mendiversifikasi sumber energi selain Rusia. Hal ini dilakukan oleh Uni Eropa sebagai upaya untuk mengurangi ketergantungan. Melihat potensi proyek South Stream akan mengancam diversifikasi Uni Eropa, maka pada tahun 2011 Uni Eropa menetapkan Third Energy Package. Dengan adanya peraturan tersebut membuat proyek South Stream terpaksa dihentikan karena dinilai tidak memenuhi peraturan Third Enerdy Package (Dempsey, 2014).

Menanggapi hal tersebut, Rusia memilih untuk mengambil alternatif proyek baru, Turkish Stream, agar tetap bisa menguasai pasar Eropa. Proyek Turkish Stream sendiri memiliki tujuan untuk menjamin keamanan penyediaan energi ke Turki dan negara-negara di Eropa. Jalur pipa proyek Turkish Stream akan melalui Laut Hitam yang kemudian diteruskan ke Ipsala, Yunani sebagai pintu masuk ke kawasan Eropa (Gazprom, 2015). Seperti yang sudah dibahas pada BAB II, bahwa alasan Rusia memilih proyek Turkish Stream adalah letaknya yang strategis, konsumen energi Rusia terbesar kedua dan melepaskan ketergantungan terhadap Ukraina sebagai negara transit. Selain 
itu juga dengan bekerjasama dengan Turki, maka Rusia akan terhindar dari peraturan Third Energy Package milik Uni Eropa (Vygon, Grigory, dkk, 2015). Sehingga dalam pelaksanaannya berada ditangan kedua negara saja (Natural Gas World, 2016).

\subsubsection{Menguasai Pasar Energi Turki secara Penuh}

Seperti yang sudah dijelaskan sebelumnya, bahwa tujuan proyek Turkish Stream adalah untuk menjamin penyediaan energi ke Turki, tidak hanya Eropa saja. Sehingga selain pasar energi Eropa, pasar energi Turki juga menjadi perhatian Rusia. Sama pentingnya dengan pasar eropa, pada kenyataannya Turki merupakan salah satu pasar ekspansi utama gas alam Rusia pada tahun 2020an (Stern, Pirani, \& Yafimava, 2015, hal.7).

Sebagai negara yang mengimpor hampir semua kebutuhannya energinya, maka Turki dapat dijadikan sebagai target pasar energi bagi Rusia. Dalam hal gas alam, Turki mengimpor hampir 99\%. Pada tahun 2014, Turki mengimpor gas alam sebanyak 49,173 juta meter kubik, di mana 50\% diimpor dari Rusia, 18\% dari Iran dan 125 dari Azerbaijan. Konsumsi gas alam Turki akan terus mengalami kenaikan dan diperkirakan mencapai $70 \mathrm{bcm}$ di tahun 2030 (Santos, 2015).

Mengetahui tingginya permintaan gas alam dari Turki, maka dalam proyek Turkish
Stream tersebut membuat satu rangkaian khusus yang ditujukan untuk memenuhi kebutuhan gas alam Turki. Dalam rangkaian tersebut nantinya akan disalurkan sebanyak 15,75 bcm/tahun (Roberts, 2015). Sebagai pemasok gas utama, maka dapat diprediksi bahwa Turki akan bergantung lebih dari 70\% pada gas Rusia (Kim \& Blank, 2015). Dengan begitu, Turki akan lebih memilih untuk tetap bergantung pada Rusia karena Turki akan menerima langsung gas alam dari Rusia.

Oleh karena itu Rusia juga dapat mengontrol lebih dari sekadar pertumbuhan pasar Turki. Selain itu secara geopolitik pun Rusia menjadi lebih dekat dan dapat mempengaruhi Turki dan sekitarnya.Sehingga dengan begitu Rusia dapat menghalangi masuknya pasokan energi dari negara Asia Tengah (Koch, 2015).

\subsubsection{Menghalangi Negara Asia Tengah Masuk dalam Pasar Energi Eropa maupun Turki}

Bagi Rusia salah satu tujuan utama dari proyek South Stream sebenarnya adalah untuk mencegah proyek Nabucco dan TGI (TurkeyGreece-Italy) untuk menyalurkan gas dari kawasan Kaspia ke pasar Eropa melalui Turki (Baran, 2008, hal. 9). Pada kenyataannya, Turki juga terlibat sebagai penghubung beberapa pipa gas, seperti Nabucco, TANAP dan TAP yang merupakan rangkaian dari Southern Gas Corridor. Southern Gas Corridor tersebut merupakan proyek diversifikasi sumber gas alam yang dilakukan 
oleh Uni Eropa, Turki dan negara-negara Asia Tengah dan Timur Tengah seperti Azerbaijan, Iran dan Turkmenistan (Tagliapietra, 2014).

Dalam proyek Southern Gas Corridor tersebut, Turki dan Azerbaijan akan membawa gas alam dari Kaspia melalui jalur TANAP ke Perbatasan Turco-Yunani dan melalui jalur TAP menuju Eropa. Tentu saja ini sangat mengancam proyek South Stream milik Rusia. Dengan mengubah rute South Stream melalui Turki, Rusia bertujuan untuk menyerang Azerbaijan dan eksportir lain dari Asia Tengah untuk masuk ke Eropa. Namun setelah proyek South Stream berhenti dan digantikan oleh proyek Turkish Stream, maka peluang Rusia untuk menguasai Turki semakin besar (Kim \& Blank, 2015).

Pada dasarnya, baik proyek Turkish Stream maupun proyek SGC masih dalam tahap pengerjaan konstruksi rangkaian pertama dan diprediksi selesai antara tahun 2017 hingga 2019. Meskipun belum terlihat hasil nyatanya, namun bisa dikatakan proyek Turkish Stream lebih unggul dibandingkan proyek SGC dari segi jumlah gas alam yang disalurkan untuk Turki maupun Eropa.

\section{Pada proyek Turkish Stream}

berkapasitas $63 \mathrm{bcm}$, di mana $14 \mathrm{bcm}$ untuk konsumen Turki dan sekitar $50 \mathrm{bcm}$ disalurkan ke perbatasan antara Turki dan Yunani (Gazprom, 2015). Sedangkan TANAP menyalurkan sekitas $16 \mathrm{bcm}$ pada tahap awal, kemudian naik menjadi $23 \mathrm{bcm}$ di tahap selanjutnya pada tahun 2023, $31 \mathrm{bcm}$ di tahun 2026, dan di tahap terakhir direncanakan menyalurkan sebanyak $60 \mathrm{bcm}$. Gas alam ini berasal dari Azerbaijan kemudian disalurkan ke Turki dan Eropa (Website resmi TANAP, 2017). Pada proyek TAP kapasitas awal sebesar $10 \mathrm{bcm}$ atau setara dengan konsumsi energi sekitar 7 juta rumah di Eropa. Kedepannya, akan dilakukan penambahan dua stasiun kompresor menjadi lebih dari $20 \mathrm{bcm}$ karena pasokan energi tambahan mulai beroperasi di wilayah Kaspia (Website resmi TAP, 2017).

Dapat disimpulkan bahwa sejauh ini proyek Turkish Stream yang menyalurkan gas alam lebih besar dari TANAP maupun TAP. Sehingga jumlah konsumsi gas alam negaranegara Uni Eropa maupun Turki akan lebih banyak diambil dari proyek Turkish Stream. Terlebih dalam proyek Turkish Stream, Rusia memberikan satu rangkaian khusus untuk Turki berkapasitas $14 \mathrm{bcm}$. Bahkan di rangkaian pertama Turkish Stream akan menyalurkan 15,75 $\mathrm{bcm}$ dengan melewati Turki dan Yunani. Dapat dikatakan bahwa kedepannya Turki akan sangat bergantung pada Rusia. Dengan begitu Rusia dapat memanfaatkan ketergantungan tersebut untuk menekan Turki untuk mengabaikan TANAPTAP dan memblokir SGC sehingga tidak dapat masuk ke pasar Eropa (Kim \& Blank, 2015). Sehingga dengan begitu Rusia tetap menjadikan dirinya sebagai penguasa pasar Eropa dan juga Turki. 


\section{Kesimpulan}

Berdasarkan pembahasan di atas, dapat disimpulkan bahwa terdapat tiga kepentingan yang ingin diraih oleh Rusia. Kepentingankepentingan tersebut antara lain, mendominasi pasar energi Eropa melalui Turki, menguasai pasar energi Turki secara penuh dan menghalangi negara Asia Tengah masuk dalam pasar energi Turki maupun Eropa.

Dipilihnya Turki sebagai partner baru Rusia dikarenakan posisi yang strategis sehingga dapat menggantikan Ukraina sebagai negara transit. Selain itu juga karena Turki menjadi negara importir energi terbesar kedua Rusia. Dapat dikatakan Turki akan menjadi partner penting bagi energi Rusia di masa depan.

Rusia melihat negara-negara Asia Tengah, seperti Azerbaijan, sebagai ancaman yang dapat mempengaruhi politik-ekonomi Rusia. Terlebih dengan adanya diversifikasi sumber energi Uni Eropa dan Turki. Sehingga diperlukan proyek Turkish Stream untuk membendung masuknya produsen energi dari Asia Tengah. 


\section{Daftar Pustaka}

ABCNews. (2015, November 25). Turkish F-16 fighter jets shoot down Russian warplane near Syrian border. Diambil kembali dari ABC News: http://www.abc.net.au/news/2015-11-24/ turkey-shoots-down-jet-near-syrian-border/6970776

Banciu, R. I. (2015). South Stream Project and the Ukrainian Factor. Romanian Journal of European Affairs, 55-69.

Baran, Z. (2008). Security A spect of the South Stream Project. Center for Eurasian Policy, Hudson Institute.

BBC Indonesia. (2015, November 26). Hubungan Turki-Rusia : Meski tidak perang, tapi ada konsekuensi. Diambil kembali dari BBC Indonesia: http://www.bbc.com/indonesia/ dunia/2015/11/151126_dunia_pariwisata_rusia

BBCnews. (2014, Desember 1). Russia drops South Stream gas pipeline plan. Diambil kembali dari BBCnews: http://www.bbc.com/news/world-europe-30283571

BBCNews. (2015). Turkey Shoots Sown Russian Warplane on Syria Border. Diambil kembali dari BBC News: http://www.bbc.com/news/world-middle-east-34907983

Dempsey, J. (2014, Desember 4). Europe's Energy Strategy and South Stream's Demise. Diambil kembali dari Carnegie Europe: http://carnegieeurope.eu/strategiceurope/?fa=57386

DWnews. (2016, 06 28). Turkey seeks to normalize relations with Russia. Diambil kembali dari DW.com: http://www.dw.com/en/turkey-seeks-to-normalize-relations-with-russia/a19361845

Ellis, V. (2014, Juni 9). Bulgaria stops building on South Stream gas pipe. Diambil kembali dari Energy Live News: http://www.energylivenews.com/2014/06/09/bulgaria-stops-building-on -south-stream-gas-pipe/

Gazprom Company. (2015). Delivey Statistic of Gas Supplies to Europe. Diambil kembali dari http://www.gazpromexport.ru/en/statistics/

Gazprom Press Release. (2016, Oktober 10). Alexey Miller : legal framework for TurkStream established. Diambil kembali dari Gazprom: http:/www.gazprom.com/press/news/2016/ october/article288285/

Gazprom Press Release. (2016, Desember 8). Construction contracr signed for first string of TurkStream's offshore section. Diambil kembali dari Gazprom: http://www.gazprom.com/ press/news/2016/december/article295329/

Gazprom Press Release. (2016, September 29). Gazprom receives survey permit for two strings of TurkStream in Turkey's territorial waters. Diambil kembali dari Gazprom Website: http:// www.gazprom.com/press/news/2016/september/article287231/

Gazprom. (t.thn.). South Stream : Ensuring Europe's Future Energy Security. Gazprom.

Gidadhubli, R. (2003). Russia : Oil and Politics. Economics and Political Weekly, Vol. 38, No. 21, 24-30.

Hungarian Spectrum. (2013, Desember 12). Russia and The European Union on a collision course over The South Stream Pipeline. Diambil kembali dari Hungarian Spectrum: http:// hungarianspectrum.org/2013/12/12/russia-and-the-european-union-on-a-collision-courseover-the-south-stream-pipeline/

Kementerian Keuangan Rusia. (2016). Annual Report on Execution of The Federal Budget. Moskow. 
Koch, F. (2015). Turkish Stream and Its implication for the EU. European Policy Brief, 1-9.

Maltsev, Y. (2014, April 30). Russia sues EU over Third Energy Package . Diambil kembali dari Reuters: https://www.rt.com/business/156028-russia-sues-eu-energy/

Movchan, A. (2015). Just an Oil Company? The True Extent of Russia's Dependency on Oil and Gas. Diambil kembali dari http://carnegie.ru/commentary/? fa $=61272$

Natural Gas World. (2016, Agustus 16). Turkish Stream on Putin's Term. Natural Gas World, hal. 2.

Piebalgs, A. (2009). EU-Russia Energy Relations : Common Goals and Concerns. EU-Russia Center Review.

Rainford, S. (2016, 07 02). After Erdogan apology, Russia brings Turkey in from the cold. Diambil kembali dari BBC News: http://www.bbc.com/news/world-europe-36689801

Roberts, J. (2015). The Impact of Turkish Stream on European Energy Security and The Southern Gas Corridor. Atlantic Council Global Energy Center.

Santos, A. (2015, Juni 5). Turkey : Turkish Energy Market 2015. Diambil kembali dari Mondaq : Connecting Knowledge \& People: http://www.mondaq.com/turkey/x/395770/ Oil+Gas+Electricity/Turkish+Energy+Market+2015

Shaffer, B. (2009). Energy Politics. Pennsylvania: University of Pennsylvania Press.

sputniknews. (2014, Juni 9). Serbia forced to halt South Stream gas project over EU's stance on Ukraine. Diambil kembali dari sputniknews: https://sputniknews.com/ voiceofrussia/2014_06_09/Serbia-forced-to-halt-South-Stream-gas-project-over-EUs-stance -on-Unkraine-8833/

Tagliapietra, S. (2014). The EU-Turkey Energy Relations After the 2004 Ukraine Crisis Enhancing the Partnership in a Changing Environment. Italy: Fondazione Eni Enrico Mattei.

URS. (2014). South Stream Offshore Pipeline - Turkish Sector : Non-Technical Summary. United Kingdom.

Vygon, G. e. (2015). Turkish Stream : Scenarios of Bypassing Ukraine and Barriers of European Commisision. Moscow: Vygon Consulting.

Vygon, Grigory, dkk. (2015). Turkish Stream : Scenatios of Bypassing Ukraine and Barriers of European Commission. Moscow: Vygon Consulting. 